Estudios de Psicología, vol. 29, núm. 1, 2008, pp. 81-102.

\title{
La entrada al mundo a través de las artes temporales.
}

\author{
Español, Silvia.
}

Cita:

Español, Silvia (2008). La entrada al mundo a través de las artes temporales. Estudios de Psicología, 29 (1), 81-102.

Dirección estable: https://www.aacademica.org/silvia.espanol/108 ARK: https://n2t.net/ark:/13683/pHOV/RXr 


\title{
La entrada al mundo a través de las artes temporales
}

\author{
SILVIA ESPAÑOL \\ Universidad de Buenos Aires / Consejo Nacional de Investigaciones Científicas y Térnicas<smiles>C#CCOc1ccccc1</smiles> \\ Resumen \\ En este trabajo se analiza la elaboración del sonido y del movimiento que caracteriza a la estimulación que \\ el adulto dirige al infante durante sus primeros meses de vida. La mayoría de las investigaciones del área han \\ puesto el acento en el análisis del sonido y si han prestado atención al movimiento del adulto ha sido en función \\ de sus rasgos musicales, por ej., el ritmo. De modo diferente, aqui se comentan observaciones obtenidas a través \\ del microanálisis de la elaboración del movimiento de un adulto, en una escena de interacción espontánea con un \\ bebé de 7 meses, realizado con el sistema Laban de análisis del movimiento proveniente de la danza. \\ Palabras clave: Desarrollo, infancia, artes temporales, música, danza, Análisis Laban del Movimien- \\ to.
}

\section{Opening to the world through temporal arts}

\section{Abstract}

The production of sound and movement that characterises infant-directed stimulation by adults during their first months of life is analysed. Most of the research in this area has been centred on analysing sound, and if attention has been paid to the adult's movements, it has tended to be as a function of its musical traits -rbythm, for example. As an alternative, comments are made here on observations obtained after microanalysing the elaboration of an adult's movements using the Laban Movement Analysis, in a situation of spontaneous interaction with a seven-month-old baby.

Keywords: Development, infancy, temporal arts, music, dance, Laban Movement Analysis. 
De a ratos somos islas o mónadas incapaces de contactar con quienes nos rodean; casi todos conocemos de una manera u otra el aislamiento y la soledad. Pero nuestra soledad es una soledad poblada por lo mismo que aún siendo islas somos islas habitadas. Nos constituimos con otros y no hay biografía ni yo posible sin la remisión a otras personas. Nuestros modos de estar con los otros son muchos y variados, absurdo intentar clasificarlos, pero hasta los más cercanos e íntimos, en realidad especialmente los más cercanos e íntimos, empiezan a constituirse desde el nacimiento en un escenario provisto por ciertos rasgos de especie. Parte de la tarima de este escenario lo constituye nuestra cualidad de ser seres altriciales, indefensos y pocos desarrollados en el momento de nacer. Todos nosotros pasamos por una estancia de inmadurez prolongada, un período de neonatenia extensa, en el cual precisamos del cuidado del otro. Y los sonidos y movimientos que recibimos y emitimos durante ese período de crianza forman el campo sobre el que se labrarán nuestros futuros modos posibles de estar con otros. No voy a defender la idea estrecha de que todo está ahí, al inicio, programado y preestablecido. No hay desarrollo alguno sin cultivo de los estados iniciales. Pero si plantearé que experiencias sensorio-motoras, corporales, no verbales, temporales, traman desde el nacimiento modos sensibles de estar con los otros que no se pierden, ni siquiera cuando adquirimos el lenguaje. Que esas experiencias, las más tempranas, están favorecidas por el diseño de especie a la par que bañadas de cultura. Y que son más cercanas a la música y a la danza que al lenguaje. Sostendré, siguiendo las ideas de Trevarthen, de Dissanayake y de Stern, que la génesis de los modos de estar con los otros está más cerca de la percepción del tiempo que de la formación de conceptos. Y como del tiempo del sonido y del tiempo del movimiento están hechas las artes de la música y de la danza, me serviré de ellas para proponer una forma de abordaje de las interacciones tempranas entre el adulto y el bebé. Me ocuparé especialmente del modo en que los adultos despiertan la atención de sus bebés, los llaman o reclaman a un mundo emocional e interpretan estímulos provenientes del medio provistos tan sólo de pautas de mirada, sonidos y movimientos. El abordaje que propondré concierne a la psicología del desarrollo, sin embargo, es fruto también de hipótesis evolucionistas acerca de la música y acerca de los modos de estar con los otros.

\section{Música e intersubjetividad en la psicología evolucionista}

La psicología evolucionista mira hoy con interés a la música. Algunas teorías destacan su nulo valor adaptativo. La "nueva síntesis" (entre la teoría darwiniana y la psicología cognitiva) la considera un subproducto de otras conductas adaptativas. Sostiene que nuestra mente está específicamente adaptada para la vida en pequeñas bandas de cazadores-recolectores, que es la forma en que más tiempo vivió la humanidad, y que dista mucho de ser un sistema homogéneo. Se asemeja, más bien, a una navaja suiza: está equipada con módulos para los principales modos de interpretar el mundo, relevantes en el pleistoceno (para la interpretación del mundo de los objetos, de las personas, del mundo natural, de los artefactos). La música, sin embargo, no se encuentra en el mismo nivel que estos mecanismos específicos diseñados por la evolución, podría desaparecer de nuestra existencia y el resto de nuestro estilo de vida quedaría intacto. La música no es una adaptación sino una tecnología que no confiere ninguna ventaja a la supervivencia. Si subsiste, y si casi parece tan ubicua como el lenguaje, es porque se trata de un dulce exquisito preparado para deleitar otras facultades mentales: entre ellas, el lenguaje, los reclamos emocionales (sexuales, filiales) y el control motor. Esta es la famosa hipótesis de la música como "una torta de queso", rica pero no esencial para la supervivencia, de Pinker (1997/2001). 
Otras teorías encuentran que la música tiene un valor adaptativo, aunque en un sentido algo estrecho. Miller (2000), por ejemplo, la supone operacional en procesos evolutivos de selección sexual. Cree que la música, así como la creatividad y el disfrute artístico se originaron en el pleistoceno, en el proceso de elección, por parte de hombres y mujeres, de sus parejas sexuales. Llega a pensar que la selección sexual es responsable de que la mente humana sea un órgano cuyas capacidades exceden las necesidades de supervivencia de las sabanas de África. La música, como el humor, la apetencia por contar historias, el chisme, el arte, el lenguaje adornado, las ideologías imaginativas, la religión y la moralidad, presentes en todas las culturas, parecen difíciles de explicar en términos de beneficios para la supervivencia; sin embargo, pueden entenderse como productos de la selección sexual. Son productos de una mente que, en realidad, es un sistema de entretenimiento casero muy colorido y más potente de lo necesario que evolucionó para ayudar a nuestros antepasados de la edad de piedra a atraerse sexualmente los unos a los otros. Miller supone que encontramos atractivas aquellas cosas que sólo pudieron haber sido producidas por personas con cualidades atractivas y de alta adaptación, como la salud, la energía, la resistencia, la coordinación entre la mano y el ojo y el fino control motor, la inteligencia, la creatividad, el acceso a materiales escasos, la capacidad para aprender destrezas difíciles y mucho tiempo libre. En tal sentido, hacer que las "cosas sean especiales" significa hacerlas difíciles de realizar, de manera que revelen algo especial en quien las hace. Se sigue de ahí que casi todo puede volverse artístico si se ejecuta de una manera que lo torne difícil de imitar, ya sea un objeto manufacturado o un modo de cantar o de bailar. Uno casi puede ver corriendo desde la sabana ardiente hasta el asfalto que soporta rascacielos al homo pugnax, utilitarista, hedonista, competitivo, sexualmente atractivo.

Pero la psicología evolucionista transita también otros senderos. Huron (2003) argumenta que la hipótesis más plausible es que el valor adaptativo de la música radique en su capacidad para establecer lazos sociales. La música logra aunar ánimos, es esencial para la vida grupal porque al permitir sincronizar el ánimo de muchos individuos prepara al grupo para actuar al unísono. Es ubicua porque favorece el lazo social entre individuos que requieren de la acción y participación conjunta para poder sobrevivir. También Steven Mithen, en su sorprendente libro The Singing Neanderthals: The Origins of Music, Language, Mind, and Body, sostiene el valor de la música para el establecimiento de lazos sociales. Pero además, asocia la musicalidad con el género Homo. Supone que la musicalidad emergió con el Homo Ergaster y alcanzó su máximo despliegue en el Homo Neardental. Sin embargo, asegura que la música propiamente dicha nació con el Homo Sapiens. Mantendré esta distinción, no precisa pero presente en muchos trabajos, entre música y musicalidad (o rasgos musicales) porque permite rescatar atributos musicales que cualifican a eventos o acciones dispares de las cuales se podría discutir su pertenencia a la categoría música. Me refiero a rasgos tales como el ritmo, que se manifiesta en muchas actividades, como correr o martillar, o los contornos melódicos que caracterizan el habla. Mithen describe un sistema originario de comunicación -el Hmmmm - que se caracterizó por haber sido bolístico, manipulativo, multimodal, mimético y musical. Supuestamente fue el sistema de comunicación que se inició hace unos 1,8 millones de años con el Homo Ergaster, se desarrolló en las otras especies Homo tempranas, llegó a su máximo despliegue en el Homo Neardental y en el Homo Sapiens se separó en música y lenguaje. Considera que en la actualidad persisten remanentes del Hmmmm. El principal: el habla dirigida al bebé, mejor dicho, la performance (o espectáculo) que los adultos dirigen a los bebés. En la calificación de la estimulación adulta como performance, Mithen sigue a Dissanayake. Aunque necesariamente especulativa, la 
hipótesis de Mithen resulta sugerente. Aunque él no pretenda decir nada nuevo acerca de la estimulación o las performances que los adultos dirigen a los bebés, al enlazarlas con el Hmmmm abre la puerta a la exploración de rasgos hasta ahora poco considerados. Más adelante volveré sobre este tema.

Algunos teóricos (incluido Mithen) vinculan la cualidad del mundo social humano con la precocidad del nacimiento. $Y$ otros vinculan a ambas -la cualidad del mundo social y la precocidad del nacimiento humano- con el origen de la música (y de la danza). Una de las hipótesis más plausibles acerca de cuáles fueron las causas que determinaron el nacimiento precoz de los humanos es que el cambio en la configuración de la pelvis y el estrechamiento del conducto natal (productos de la evolución de la postura vertical y de la locomoción bípeda) limitaron la posibilidad de crecimiento intrauterino del cráneo acelerando el nacimiento. Independientemente de que esta hipótesis resulte adecuada, el nacimiento precoz y la continuación de la gestación fuera del útero tuvieron efectos drásticos en la evolución del hombre; efectos comparables, tal vez, con los producidos por el bipedismo en la capacidad para manipular objetos y para fabricar herramientas al dejar las extremidades superiores libres. Pero la precocidad del nacimiento marcó decisivamente otro aspecto del mundo humano: el social. Porque de la inmadurez se derivan la dependencia y la supervisión sociales. Y dado que la inmadurez se asocia con el andamiaje parental omnipresente desde el nacimiento, consecuentemente modificó también las características de los adultos de la especie (Rochat, 2000/2004).

Una de las marcas decisivas fue el cambio radical en la modalidad del vínculo con el congénere. El andamiaje parental abrió las puertas a que un ser (el indefenso) y otro ser (su cuidador) entraran en un contacto íntimo de sentimientos amasados casi con una única materia: el tiempo. Sentimientos que luego se extenderán más allá del universo volcado hacia sí mismo de la díada adulo-bebé transformando y coloreando múltiples aspectos de la vida adulta. Esta es la hipótesis de Ellen Dissanayake (2000a) para quien el extenso período de neonatenia de la cría humana creó una presión selectiva para la proximidad psicológica y para los mecanismos cognitivos que aseguraran un prolongado y mejor cuidado maternal. Fue el motivo de la elaboración de conductas filiativas presentes en otros primates - como expresiones faciales, gestos, movimientos y sonidosmediante su moldeado dinámico, rítmico y trasmodal. Para atraer la atención del bebé los padres elaboran sonidos y movimientos ordinarios: repiten (frases, movimientos, sonidos, expresiones faciales) y exageran (sus contornos melódicos, su amplitud, su duración y las pausa entre ellos). La elaboración -que conlleva saliencia, novedad, expectativa y por tanto emoción- de lo que de por sí ya son pautas filiativas tiene la virtud de conducir directamente a un estado de mutualidad inherentemente placentero y da lugar al establecimiento de las primeras experiencias de intersubjetividad entre el bebé altricial y el adulto atento.

Pero además, con la elaboración germina el arte. A lo largo de la evolución humana-sugiere Dissanayake- las sociedades se han apropiado de la capacidad de responder a tales elaboraciones -repeticiones y exageraciones de ritmos y modos que por medio del cambio y la novedad crean una expectativa y por tanto engendran y configuran una trayectoria emocional-y las han usado en las ceremonias rituales y en las tempranas artes temporales -la música y la danza-. En consonancia con la llamada estética darwiniana, Dissanayake sugiere que las artes usan formas, colores, movimientos y sonidos que fueron ancestralmente (y aún pueden ser) relevantes para nuestros intereses vitales y que tienen ciertos significados asociados (los movimientos fuertes, vigorosos y controlados están asociados con vitalidad, salud, juventud, así como los colores brillantes y ciertos ritmos). Estos rasgos y temas provocan interés por sí mismos y a menudo gratifican: son 
"buenos para mirar, para escuchar, para tocar" porque están asociados con referentes biológicamente útiles y fácilmente provocan una respuesta emocional. Y es justamente por sus cualidades emocionales que son usados en el arte. Pero ellos son sólo ingredientes o rasgos protoestéticos. El trabajo artístico hace algo más sobre esas cualidades de objetos u eventos: los elabora -moldea, exagera, enfatiza- de forma tal que se vuelven más coloridos o vívidos, complejos, armoniosos, irresistibles o movedizos que su contraparte no-estética. Ahí empieza la labor estética: cuando "algo se hace especial" en virtud de su elaboración. Pero sólo empieza ahí. Porque la elaboración es apenas el primer paso en el camino hacia la producción o recepción estética. Sin embargo, lo esencial para mi argumentación es que ese primer paso se da al extrapolar "allá afuera" -en el mundo externo y compartido por la comunidad - los rasgos y procesos que caracterizan la elaboración de la estimulación que los adultos dirigen a los bebés.

Dissanayake (1992, 2000a) desvincula la génesis del arte del proceso de formación simbólica. Su idea es que las primeras expresiones artísticas fueron la música y la danza. Ambas artes que no son representacionales ni simbólicas sino que son artes temporales. Es en los rituales y en las ceremonias comunales en las que se elaboran sonidos y movimientos el lugar donde emerge el arte. Su hipótesis no sigue el pensamiento tradicional según el cual las primeras expresiones de arte se encuentran en las pinturas rupestres y en los objetos figurativos de hace aproximadamente unos 30.000, cuyo carácter estético no puede desligarse de su naturaleza simbólica. Estas manifestaciones iniciales de arte son consideradas símbolos ya sea porque representan algo (como la estatuilla Hohlenstein-Stadel que, tallada en un colmillo de mamut, representa un ser mitad animal y mitad humano) o porque permiten suponer su pertenencia a un código simbólico (como la reiteración de motivos en el canto rodado Abri Cellier). Mithen, en su libro de 1996, La arqueología de la Mente. Orígenes del arte, la religión y la ciencia, defendió convincentemente la idea de que, en el desarrollo de nuestra especie, arte y símbolo se encuentran unidos. Embebido del pensamiento cognitivista clásico (él mismo señala las ideas centrales que toma de la psicología cognitiva: la pasión por lo analógico de los sistemas centrales de Fodor, la configuración de mapas transversales de Carey y Spelke, el concepto de metarrepresentación de Sperber) realiza un lúcido enlace entre la psicología y la arqueología que da lugar a la ecuación arte-símbolo. Sin embargo, diez años después, en The Singing Neanderthals. The origins of music, language, mind, and body, enlaza su análisis arqueológico con las investigaciones sobre las interacciones tempranas adulto-bebé y con los estudios en psicología cognitiva de la música, en neurociencia y en otros ámbitos aparentemente dispares. Combina todas las áreas, mezcla, asume la relevancia de las artes temporales y compone una idea, buena para escuchar, de nuestro ir haciéndonos humanos.

Mithen sugiere la indivisibilidad entre las artes temporales y las experiencias de intersubjetividad. La misma hipótesis se encuentra en la obra de Dissanayake para quien la elaboración, que está en la base de la génesis del arte, es a su vez el soporte de las primeras experiencias de intersubjetividad entre el bebé y el adulto. En las tempranas experiencias de intersubjetividad perviven los sentimientos de filiación propios de otros primates pero en ellas emerge, además, la ornamentación, la filigrana y la complejidad de los modos de sentir temporales. Una y otra vez, cada vez, en cada díada adulto-bebé de nuestro presente, nuestro pasado evolutivo se cristaliza en el entendimiento (o desentendimiento) a través del lenguaje del tiempo. Acontece especialmente durante los primeros meses de vida del bebé, en el que el hacer conjunto de la díada prescinde de los objetos del medio y todo ocurre con una pauta de mirada particular que sólo en ocasiones se reiterará en la vida: el contacto ocular extenso y demorado. Este momento, deno- 
minado por Colwin Trevarthen (1998) período de intersubjetividad primaria, es un imán para todos aquellos que de una manera u otra tienen una comprensión musical de la subjetividad humana. También el período que se inicia después, alrededor de los nueve meses (denominado período de intersubjetividad secundaria) es relevante. Pero lo es de otra manera: a esa edad los objetos se incorporan a la díada, emerge la acción conjunta y aparece por primera vez en el bebé la alternancia de la mirada, que se dirige al adulto y luego a algún objeto o evento y de nuevo al adulto. Es la apertura al mundo de la referencia y a la comunicación, a la convención social y al símbolo, iqué duda cabe de su interés! Pero el anterior, el período de intersubjetividad primaria, es la experiencia de la comunión, de los límites aún no establecidos, del saber estar y hacer con el otro sin mediación conceptual alguna. Algo, que de acuerdo con Stern (1985/1991) no perdemos, al contrario, forma el lecho de roca existencial de nuestros futuros modos de comunalidad y también de comunicación.

\section{Tiempo, música e intersubjetividad en la psicología del desarrollo}

Las experiencias de intersubjetividad primaria son un modo de contacto que no tiene la sofistificación del pensamiento ni está mediada por conceptos. Se trata sólo de percepción y acción, y de acción en el sentido básico de realización de movimientos y contacto de miradas. Sin embargo, de este modo primitivo de estar unos con otros puede decirse lo mismo que se dice de la percepción en general: tremendamente simple pero increíblemente compleja. La psicología evolucionista da el porqué de esta extrañeza: la percepción tiene un largo pasado evolutivo, el modo humano de percepción tiene un extenso recorrido filogenético; su complejidad, rapidez y facilidad radica en que, como el diablo, es vieja. Lo mismo ocurre con el modo de estar con el otro que se establece entre el bebé y el adulto. Parece una simpleza, algo casi intrascendente; sin embargo implica un saber hacer que está montado sobre una suma de pequeñas funciones mentalescorporales del bebé preparadas por la evolución para engarzar con funciones del adulto. Hay un diseño de filigrana para la interacción y la proximidad psicológica que da lugar a modos de sentir que son sofisticados no al modo de los conceptos sino del tiempo. Y, lo que considero una especulación interesante, es posible que luego, día a día adulto, reinventemos, a través del arte y en nuestras experiencias amorosas pero también en actividades simples y cotidianas, intrascendentes -como en la explosión del aplauso conjunto o en el cántico de cancha de fútbol o en las rimas infantiles o siguiendo con movimientos apenas insinuados el ritmo lejano de un tamboril o cortando cebolla- esos modos de sentir temporales.

Si esto es cierto, acercarnos a los modos más tempranos de estar unos con otros pueda tal vez permitirnos entender con más sutileza los modos posteriores, adultos. Tanto los aceptados como los inaceptados, aquellos que preferimos no considerar humanos o intentamos conjurar a través del arte, como cuando Faulkner describe los ojos de Popeye como dos bolas negras de goma blanda y fría. Lo que vengo llamando sentimientos temporales pueden describirse con términos dinámicos como agitación, desvanecimiento progresivo, fugaz, explosivo, crescendo, decrescendo, estallido, dilatado. Tienen que ver con la fugacidad_del gesto o de una idea o de un recuerdo, con la explosión de la risa o de una cachetada, con la irrupción de un torrente de luz o de un torrente de pensamientos, con la demora de la caricia o el deslizamiento suave de la caída de un panadero, con la electricidad pulsátil de un teléfono sonando insistentemente o de una pierna temblando, con la aceleración del pensamiento o el acelerarse de las aguas de un río, con la tensión de apuntar con una gomera y la distensión de soltar la cuerda, la excitación ante el pájaro quie- 
to y tieso. Se trata de experiencias difíciles de ser descritas a través de palabras, en las que se aúnan la diversidad de sensaciones provenientes de diferentes modalidades, auditiva, visual, táctil, kinestésica, en función de su perfil de activación.

Los sentimientos temporales o afectos de la vitalidad son, de acuerdo con Stern (1985/1991, 2000), perfiles de activación en el tiempo. Cambios pautados de la intensidad de la sensación y del tono hedónico en el tiempo que inciden constantemente en el organismo ya que están involucrados en todos los procesos vitales (en el respirar, sentir hambre, caer dormido y salir del sueño) en cualquier evento percibido (en el timbre de un teléfono que irrumpe en el silencio, en el ir y venir de emociones y de pensamientos) en cualquier acción o movimiento (en llevarse el dedo a la boca, en aplaudir, huir, sentarse, caminar o tocar el brazo de un amigo, o de un enemigo). Los sentimientos temporales son esencialmente una experiencia en la que se aúna la diversidad de sensaciones provenientes de diferentes modalidades en función de su perfil de activación.

No son emociones en el sentido de las emociones básicas darwinianas, como la ira, el miedo, la alegría, la tristeza, etcétera. Pero pueden acompañarlas: puedo sentir una tristeza evanescente o una alegría fugaz o una irrupción creciente de ira. $\mathrm{O}$ pueden presentarse sin ellas: como en los espectáculos de títeres en los que, aunque en los rostros no se exprese emoción alguna, a partir de los perfiles de activación que surgen de la manera en que se mueven percibimos modos letárgicos, violentos o eléctricos. En cambio, otras manifestaciones artísticas más representativas o narrativas, como la teatral, son casi una cocina del mundo emocional darwiniano; reflejan aquella expresión que define al hombre como un gourmet de emociones, un ser que dedica gran parte de su actividad a intentar entender y paladear las emociones propias y ajenas. La música se parece más a los espectáculos de títeres.

La idea de que la música no expresa emociones básicas no es nueva. En el siglo XIX lo dijo Friderich Nietzsche (ver Picó Sentelles, 2005 y en este volumen). Y Daniel Stern, retomando ideas de Susane Langer, vuelve a indicarnos la naturaleza temporal del sentimiento que expresa la música de una manera que recuerda el decir nietszcheano (ver Español, 2006). De acuerdo con Stern (1985/1991), la música esencialmente expresa sentimientos temporales. En realidad, la música -el arte del sonido en el tiempo- y la danza -el arte del movimiento en el tiempo- son las artes que expresan con maestría los sentimientos temporales. Por eso intuye que lo que experimenta el infante en su mundo interpersonal, especialmente desde el nacimiento hasta los seis meses, se asemeja a lo experimentamos al escuchar música o al ver un espectáculo de danza abstracta. No hay todavía trama o sentimientos de personajes como amor, odio o tristeza, no hay aún narrativa, no hay siquiera objetos mediando el contacto, sino tan sólo un otro con el que se comparten patrones temporales, el ir y venir de tensiones y distensiones, sutiles ascensos y descensos, bruscas excitaciones y disrupciones, repeticiones, variaciones, pulsos certeros, melodías, anticipaciones e incertidumbres.

He señalado semejanzas entre las artes temporales y el mundo social experimentado por el infante. Pero las diferencias no son menores. Las expresiones artísticas están involucradas en el sentido de la vida, en el modo en que entendemos el mundo o en la perplejidad que nos produce, están transidas del espíritu de la época y constreñidas también por pautas sociales que permiten o proscriben formas y por criterios estéticos que varían cultural e históricamente. Todo esto está muy lejos de la infancia, pero un poco menos lejos (aunque siga siendo muy distante) de las performances que los adultos dirigen a los bebés. Ya que ellas se generan con los elementos de las artes temporales de la cultura en la que han crecido. Los adultos cuando nos dirigimos a los bebés, hablamos, gesticulamos, tocamos y/o nos movemos de manera diferente a cuando nos dirigimos a otros 
congéneres. Este hecho parece tener cierto grado de generalidad. Tal homogeneidad de comportamiento probablemente se deba a que la elaboración de la estimulación parental es producto de nuestro pasado evolutivo. Pero las modificaciones de la estimulación parental muy probablemente varíen de una cultura a otra en función de las características particulares que las artes temporales despliegan en la cultura en que el adulto está inmerso. En Shifres (2007) pueden encontrarse datos empíricos que avalan esta hipótesis.

Un último comentario, ciertamente especulativo, sobre los sentimientos temporales. Stern nos dice que el mundo conceptual no es ajeno a los sentimientos temporales. En la adultez, podemos percibir el sentimiento temporal de irrupción tanto en una secuencia acelerada de pensamientos como en la entrada de un torrente de luz por la ventana. Aunque no lo diga explícitamente (al menos hasta donde tengo conocimiento), podemos suponer que no sólo en la adultez sino desde que empieza a emerger en la infancia el ámbito conceptual está mezclado con experiencias sensorio-motoras temporales. Ahora bien, si desde el inicio el mundo conceptual y el temporal están mezclados de forma tal que los sentimientos temporales afectan la presentación de los pensamientos, entonces también puede ocurrir que el mundo conceptual modifique nuestros sentimientos temporales, y que existan formas de pensamiento y sensibilidad en las que no se pueda saber, ni tenga sentido preguntarse, qué porción es de cada uno. Porque como dice Mithen (2006) la combinación y la confusión de criterios y fines es la condición normal y original de la humanidad. Cuando hablamos, gritamos o susurramos impregnamos al lenguaje de temporalidad y música e invitamos al otro a compartir patrones temporales. Hay ahí concepto y experiencia temporal, musical, a la vez. Lo mismo ocurre en la canción popular. No hemos de restringir el lenguaje a un código abstracto o a un conjunto de reglas sobre representaciones. El lenguaje no es sólo eso. Seguramente no lo es al inicio de la vida, en que lo esencial es el sonido del lenguaje (el timbre, la melodía, el ritmo de la voz), pero después también, en la adultez, sucede a veces que, en términos nietzscheanos, el sonido se torna una grieta en la estructura conceptual y la composición de palabras imita a la música. En ocasiones decimos cosas tales como "todo eso es cierto pero busco tu mano" y escuchamos algo más que conceptos encadenados. En la adultez, nuestros modos de estar y comprender a los otros no son sólo temporales, ni musicales. Es cierto que a veces tienen la sensibilidad de un choque entre piedras, pero otras son como formas de sonidos que atraviesan conceptos, como el lenguaje musicalizado.

\section{Detalles para armar}

Hay algo de la psicología del desarrollo actual que resulta muy atractivo, al menos para mí. Se trata de los datos que ofrecen los sesgados y mosaicos estudios de laboratorio con bebés así como los estudios microgenéticos de la interacción entre adulto y bebé en situaciones menos artificiales. Ambos son buenos detalles para empezar a armar una historia plausible, contemporánea, de la génesis y naturaleza de los modos de sentir sutiles, bruscos y complejos de los que somos capaces las personas. A continuación comentaré sesgadamente algunas de las cosas que sabemos, o suponemos con cierto grado de certeza, acerca del tiempo y la musicalidad tanto en lo que el bebé es capaz de percibir y hacer, como en lo que el adulto suele hacer cuando está con un bebé, como en lo que ocurre en la propia interacción. Como podrá observarse los datos que reseñaré tienen un cierto parecido de familia. No esculpen un bebé cognitivo, conceptual desde el inicio, sino que destacan el dominio perceptivo. Son datos que resaltan lo que está a la vista, en la superficie, y no en abismos ocultos. 


\section{Temporalidad y musicalidad}

Hace unos 30 años que la hipótesis de que los humanos al nacer somos una tábula rasa viene refutándose. La investigación indica que venimos al mundo con un conjunto de predisposiciones estimulares hacia parámetros que caracterizan a las personas, como el complejo estimular que identifica el rostro humano. Venimos también con predisposiciones estimulares hacia parámetros que caracterizan los modos de actuar de las personas. Estos son los que me interesan. Como parte de nuestro diseño "para la relación", contamos con una precoz sensibilidad a la percepción de contingencias y de concordancias. Un aspecto de nuestro diseño de especie basado en la sensibilidad al tiempo.

Los bebés se muestran altamente sensibles a la percepción de contingencias. En situaciones de laboratorio se ha demostrado que, a la temprana edad de dos meses, cuando se establece una relación contingente y sistemática entre un esquema del bebé y una estimulación exterior contingente, muestran con claridad respuestas sociales como gorjeos y sonrisas. Por ejemplo, si se ata un extremo de una soga al pie del bebé y el otro extremo a un patito de juguete que se encuentre a su vista; cuando el bebé percibe que al mover el pie el patito se mueve, sonríe y balbucea. Es decir, los bebés dan respuestas sociales inequívocas a objetos inanimados que reaccionan contingentemente. Llamativamente, las contingencias imperfectas son experimentalmente más eficaces en la evocación de respuestas sociales que las contingencias perfectas. He aquí una de las semillas de la interacción social, porque en el mundo cotidiano del bebé los entes que dan respuestas temporalmente contingentes a sus acciones son sus congéneres. $Y$ las estimulaciones contingentes que provienen de las personas son las más atractivas ya que tienen siempre un carácter imperfecto (Rivière,1986/2003; Watson y Rammey, 1972).

La preferencia del bebé a estímulos que son respuestas contingentes a sus acciones fue el fenómeno temporal central para la cognición social detectado en la década del 80. Por esa misma época, Bahrick y Watson (1985) encontraron otra preferencia estimular que también caracteriza el modo de actuar de las personas y que también supone una sensibilidad al tiempo: la estimulación concordante. A veces a la concordancia se la denomina también contingencia, pero se trata de una contingencia particular entre rasgos que conforman la estimulación compleja, necesariamente multimodal, que recibe el bebé. A partir de los años 90 , se acrecienta el estudio de la estimulación concordante en el laboratorio experimental. Se observa que en situaciones artificiales a los bebés los atrae especialmente la estimulación concordante. Cuando, por ejemplo, se les presenta estímulos muy simples como (a) una esfera que se mueve y un sonido sincrónico de igual duración y (b) una esfera que se mueve y un sonido desincronizado y con una duración diferente, miran más tiempo, prefieren, la estimulación concordante, es decir, la estimulación apareada temporalmente (Lewkowicz, 1992, 2002). Las personas ofrecemos todo el tiempo estimulación concordante. No sabemos no hacerlo, intente usted generar una estimulación no-concordante simple: comience a decir "uuuuuuu" al mismo tiempo que mueve su dedo índice hacia arriba y termine primero el movimiento y luego el sonido. Como mínimo le resultará difícil. Desde el primer momento que hablamos y tocamos a nuestros bebés, les estamos ofreciendo una estimulación concordante en algún valor temporal, como la duración o el ritmo, que a ellos los atrae especialmente. Una vuelta más en la filigrana de nuestros preferencias perceptuales iniciales que nos orientan hacia un otro no representado ni quieto sino un otro en movimiento que hace cosas que atraen. 
La sensibilidad infantil al tiempo se observa también en algunas de las habilidades iniciales señaladas en el área de la psicología cognitiva de la música: como la distinción precoz, en el laboratorio, de patrones rítmicos, de contornos melódicos prototípicos y de cambios de tono, de timbre y distancias entre alturas (Trehub, 2000). Las precoces habilidades musicales del bebé se ponen en juego en sus interacciones espontáneas con los adultos: los bebés son sensibles a los cambios de tono, a los contornos melódicos y tímbricos de la vocalización parental así como a sus atributos rítmicos (Trehub, 2000 y 2003), y el pulso parece ser el elemento esencial para el acoplamiento interactivo entre ellos (Trevarthen, 2000).

Las capacidades iniciales infantiles parecen especialmente diseñadas para acoplarse con los rasgos más sobresalientes de la estimulación adulta. Cuando los adultos se dirigen a los bebés, al menos en nuestra cultura, remarcan el pulso, retardan el tiempo del habla, hacen pausas más largas y hablan más rítmicamente, con frases bien segmentadas. Tienden a usar un conjunto de cinco prototipos melódicos: usan melodías ascendentes para llamar la atención del bebé o para darle turno en un diálogo y contornos descendentes ante la sobrexcitación del niño o para finalizar el diálogo (Papôusek, 1996). Pero, además, los adultos cuando se dirigen a sus bebés ( $\mathrm{y}$ no a sus amigos, vecinos o compañeros) organizan sus sonidos y movimientos bajo la forma repetición-variación. Generan así un tipo de estimulación ideal: porque si fuese siempre igual el bebé se habituaría y perdería interés; y porque la repetición genera una regularidad que le permite anticipar el curso del tiempo, es decir, permite predecir lo que vendrá (Rivière, 1986/2003). A través de la elaboración de estímulos que cambian de una forma interesante y no totalmente predecible, los adultos despiertan la expectativa del bebé. Repiten frases, movimientos, sonidos, expresiones faciales, exagerando sus contornos melódicos, su amplitud, duración y las pausas entre ellos realizando variaciones en la intensidad, el ritmo, el tono, de forma tal que la estimulación es, al mismo tiempo, conocida pero nueva. La forma repetición-variación permite el reconocimiento de patrones de conducta que se repiten y por tanto favorece la anticipación. Pero, como las repeticiones son variadas la anticipación que genera en el bebé es una anticipación particular, no basada en la certeza sino en la incertidumbre, en la sorpresa y en la gratificación demorada de la expectativa (Dissanayake, 2001). Y así en la infancia como en la música. Porque, como dice Michel Imberty, la anticipación basada en la incertidumbre es un punto de unión entre la experiencia infantil y la experiencia musical. En las secuencias comportamentales entre adulto y bebé y en la música hay una invitación a recordar y a anticipar "con un margen suficiente de incertidumbre a fin de que cada vez se insinúe la sensación de que la repetición podría haberse no realizado, que el futuro puede ser desconocido, que la misma expectativa puede fundirse en otra, la cual a su vez puede también no ser completamente diferente." (Imberty, 2002, p. 483). El juego de repeticiones y variaciones, frecuentemente contingente con las respuestas del bebé, genera sonrisas y risas que los adultos solemos interpretar como un "hazlo otra vez" al cual no podemos resistirnos. Se producen así "reacciones circulares sociales" que dan lugar a que el ciclo se extienda temporalmente (Español, 2007a). Es posible que parte del encanto y la atracción de las reacciones circulares sociales se deba a que ofrecen la experiencia de un continuo cambiante de incertidumbre protegida. En ellas no hay un plan fijo, un modo mecánico de hacer, al contrario, pero tampoco hay puro azar impredecible. Con el juego de repeticiones y variaciones la estimulación adulta se va componiendo en el momento en función de las respuestas y participaciones del bebé de modo tal de que lo conocido se vuelve incierto y emerge lo posible. Tal vez sea uno de 
los primeros pasos hacia lo que no necesariamente ha de ser pero, sin embargo, puede ser.

Llegados a este punto podemos vincular los datos reseñados con los rasgos musicales o con la musicalidad de las interacciones tempranas. Cuando se habla de musicalidad en este contexto se hace referencia a elementos que caen en la organización temporal o en la organización espectral de la interacción (Shifres y Martínez, comunicación personal).

La organización espectral (de altura) incumbe en particular al habla que se dirige al bebé (y claro está que también a las canciones y arrullos). Los bebés son sensibles a los atributos tímbricos de la vocalización parental, así como a sus contornos melódicos. Por ello pueden reconocer el repertorio de prototipos melódicos que, como ya anticipamos, los adultos tenemos reservado para interactuar con ellos (Papôusek, M., 1996; Treuhb, 2003).

La organización temporal, en cambio, sostiene la interacción adulto-bebé a través de todas las modalidades, auditiva, táctil, visual, kinestésica. La interacción entre el adulto y el bebé está organizada temporalmente, a través de diversas modalidades, desde el inicio. A veces, los comportamientos de la díada están claramente separados en el tiempo, al modo de "protoconversaciones" en los que la alternancia de turnos es creada por ambos; otras se establece una sincronía interactiva (Stern, 1985/1991; Trevarthen, 1998 y 1999/2000). La forma repetición-variación así como el ritmo que atraviesa los movimientos y el habla son también elementos temporales musicales esenciales. Pero la organización temporal incluye también componentes dinámico-expresivos, como las aceleraciones, las pausas, los cambios de intensidad que caracterizan la repetición variada y ornamentada de la estimulación parental. Las variaciones dinámico-expresivas permiten a los adultos incrementar el nivel de excitación y tensión, realizar variaciones en un alto nivel de excitación o disminuir el nivel de tensión del bebé. Al variar la intensidad, la velocidad y la duración de sus sonidos y movimientos, al incrementar la expectativa alargando las pausas y sorprendiéndolo al acortarlas, los adultos juegan con el nivel de excitación del bebé. Pero hacen algo más: introducen a sus hijos a un mundo de sentimientos sofisticados, variopintos y cambiantes, de calma y de brusquedades, de tensa expectativa y caída ligera, de demora y desvanecimiento paulatino o de rápida y agitada aceleración. Estos sentimientos se traducen en conductas expresivas del bebé (pataleos, risas, caricias suaves, carcajadas, golpes, balbuceos) que incentivan al adulto a continuar variando y modificando, y despiertan en él sentimientos temporales semejantes a los de su hijo. De este modo se establece entre ambos una experiencia de intersubjetividad en la cual se comparten sentimientos temporales que, como señalé en el punto anterior, se asemejan a los sentimientos que expresan con maestría y sofistificación las artes temporales, la música y la danza.

\section{Percepción transmodal}

La percepción transmodal implica el tránsito de información de una modalidad sensorial a otra. Se trata de una capacidad perceptual que permite aunar diversidad de sensaciones provenientes de diferentes modalidades y establecer equivalencias entre ellas. Es una simple capacidad perceptual que, sin embargo, no es ajena al hecho de que Charles Baudelaire escriba y nosotros comprendamos "olores frescos como la piel de un niño" ni a que a Vicente Aleixandre se le ocurra la expresión "espadas como labios" o que sepamos que al decir "látigo verde" está hablando del mar. Forma parte también de los procesos que nos llevan a intuir cualidades terribles en la descripción de unos ojos como dos bolas negras de goma blanda y fría. Subyace también a los espectáculos de luz sinfónica, a la 
integración de sonido-visión en el cine (ver Shifres en este volumen) y, claro está, a la danza. Todas estas expresiones están infinitamente lejos de lo que un bebé puede comprender; pero la fácil y casi inevitable traducción del sonido al movimiento que ocurre de modo no pensado ni intencionado cuando seguimos el ritmo flexionando las rodillas está un poco menos lejos, tan sólo a varios meses de distancia. Y la capacidad de establecer equivalencias transmodales de rasgos muy globales de tiempo (también de forma e intensidad) está a su alcance: el bebé puede procesar la información que el adulto le ofrece estableciendo equivalencias temporales, por ejemplo de duración y ritmo, de las estimulaciones que recibe provenientes de diversas modalidades sensoriales (Stern, 1985/1991 y 2000). Es más, los datos de laboratorio muestran que la información presentada en forma redundante y en sincronía temporal a través de dos o más modalidades sensoriales atrae más la atención del bebé. También se ha observado que la información sensorial presentada en forma redundante realza las propiedades transmodales (como el ritmo, la intensidad o la duración) del estímulo, facilitando el aprendizaje y la discriminación de estas propiedades. En cambio, bajo condiciones de estimulación unimodal, la atención de los bebés se dirige más hacia las propiedades específicas del estímulo, como el tono, la orientación, el timbre o el color (Bahrick y Lickliter, 2000; Bahrick, Flom y Lickliter, 2002).

Las discusiones teóricas en torno a la capacidad de percepción transmodal de los bebés están vinculadas en psicología del desarrollo con las investigaciones en imitación neonatal, las cuales inmediatamente se relacionaron con la génesis de las experiencias de intersubjetividad (Kugiumutzakis, 1998; Meltzoff y Moore, 1998; Trevarthen, 1998). Pero no voy a detenerme en estos trabajos porque quiero concentrarme en los rasgos de la estimulación adulta. En este sentido, los datos de laboratorio previamente mencionados son iluminadores. Destacan como el "diseño para la relación" del bebé se enlaza con el "saber hacer" de los adultos. Porque, como vengo señalando, los adultos no sólo hablan sino que además se mueven -brindando información auditiva y visual- pero también tocan al bebé y lo mueven -ofreciéndole información táctil y kinestésica-. Utilizan todas las modalidades disponibles para ofrecer una suerte de performance o espectáculo multimedia. Los adultos al elaborar sonidos y movimientos ordinarios mediante un moldeado dinámico, rítmico y transmodal producen escenas interesantes de sonido y movimiento. Presentan una y otra vez información sensorial redundante que realza las propiedades transmodales de ritmo, intensidad y duración a las que el bebé (que de acuerdo a las investigaciones arriba reseñadas está especialmente predispuesto y capacitado para percibir) se acopla y responde con respuestas sociales que incitan al adulto a continuar. De este modo, en ciclos extendidos de reacciones circulares sociales, la percepción reiterada y variada de ritmos, intensidades y duraciones permite un fluir constante de sentimientos temporales. El bebé puede aunar, por ej., las sensaciones táctiles y auditivas que recibe cuando su madre emite sonidos, palabras u oraciones de una intensidad, una duración y un ritmo semejantes a las palmadas suaves que le da en los brazos y a los movimientos oscilantes de su cabeza hacia atrás y adelante. La misma información temporal de duración y ritmo, el mismo perfil de intensidad se le muestra una y otra vez a través de diferentes modalidades sensoriales. Y esto ocurre no sólo en un modo benevolente: de la misma manera que si los sonidos del habla materna son regulares, suaves y cadenciosos probablemente también sea así el modo en que lo toca, si el sonido de su voz es abrupto, fuerte y disruptivo posiblemente así sea también el modo que lo toca. Surgen de este modo las experiencias más básicas de "estar con el otro", aquellas en la que, insisto, se comparte la experiencia del tiempo. 
Del $\mathrm{Hmmm}$ del Pleistoceno a las escenas modernas de sonido y movimiento

Los datos reseñados reflejan el giro en el estudio de las interacciones tempranas desde su impronta lingüística, característica de la década del 70 , hacia una concepción vinculada con las artes performativas y temporales que está arrojando sus primeros resultados (Dissanayake, 2000b; Malloch, 1999/2000, Trevarthen, 1999/2000, etcétera). El análisis de la estimulación parental realizado en las últimas décadas confirma la idea de una incidencia de las artes temporales. Sin embargo, pese a que se ha destacado que los adultos brindan una abundante estimulación elaborada en todas las modalidades disponibles para el bebé, lo cierto es que lo que más se ha estudiado y se conoce es la cualidad musical-rítmica y melódica-del habla parental; y también las cualidades del canto dirigido al bebé (Longhi, 2003; Longhi y Karmilof-Smith, 2004). Y si bien es cierto que el movimiento ha sido foco de atención en el estudio de las escenas de interacción, su análisis suele restringirse a los rasgos musicales del movimiento, como el ritmo, o a su relación contingente con el sonido. Hasta donde yo sé, en lo que respecta a la descripción de la estimulación adulta, la única excepción al predominio del sonido por sobre el movimiento se encuentra en la obra de Mithen (2006) que si bien no incorpora categorías de análisis sí incluye ideas provenientes de la danza. Aún así, no se trata de una descripción directa sino de la posible extrapolación de los rasgos del Hmmmm a la estimulación adulta en tanto uno de sus remanentes que induce a mirar el movimiento de otra manera.

Mithen presta atención al movimiento en la modernidad y en nuestro pasado evolutivo. En primera instancia, realza el valor de los gestos espontáneos que acompañan al habla moderna. Los gestos espontáneos no forman parte, como las palabras, de un sistema combinatorio y jerárquico de unidades discretas; son signos bolísticos que no se sintetizan en una forma discreta y clara sino que tiene un carácter difuso y vago. Por este motivo, no sólo los diferencia del habla sino también de los gestos simbólicos intencionales que usa el hombre moderno, como la $\mathrm{V}$ para victoria. Los gestos espontáneos con los que los adultos modernos acompañamos el habla son vagos y difusos pero están cargados de significado. Mithen dice que no prestarles atención es ignorar la mitad del mensaje que llega al cerebro cuando se habla. Y también señala que cuando no hablamos los gestos espontáneos subsisten. El habla es intermitente, hablamos y callamos, y es más el tiempo que callamos que el que hablamos. En cambio, el lenguaje corporal es continuo y presenta múltiples movimientos con sutiles variaciones difíciles de categorizar. Para describir el lenguaje corporal, Mithen recurre a la danza, en particular al que fue probablemente el pensador más influyente acerca del movimiento humano del siglo XX, Rudolf Laban. Y entonces la expresión del movimiento pasa a primer plano. Porque cada frase de movimiento, cada pequeña transferencia de peso, un simple gesto de una parte del cuerpo revela algún rasgo de nuestra vida interna (Laban, 1970/1989). La expresión es la esencia de los gestos espontáneos. En los movimientos de manos, troncos, cejas, labios, cabeza de los que somos escasamente conscientes que producimos de forma continua, especialmente cuando estamos con otros, se transparentan los sentimientos que acompañan al habla. También los movimientos que acompañan o conforman nuestras acciones pueden presentar múltiples variaciones. Ya que cualquier movimiento se puede realizar con múltiples variaciones expresivas: una manzana puede comerse de una manera ávida y nerviosa, con movimientos focalizados que se desatan rápidos y repentinos o de una forma lánguida y despreocupada con movimientos dispersos suaves y lentos que casi no se completan. La misma acción adquiere en virtud de la expresión del movimiento significados diversos. 


\section{Estudios de Psicología, 2008, 29 (1), pp. 81-101}

La hipótesis de Mithen es que nuestros antecesores no lingüísticos pudieron haber usado variedades de movimientos similares al realizar actividades comunales, como la carnicería de cadáveres o el compartir la comida; o en las mímicas de tales actividades. Las secuencias de movimientos y vocalizaciones pudieron exagerarse, pudieron repetirse con múltiples variaciones expresivas y así incorporar matices de intenciones y de significados en una unidad holística básica de comportamiento. Se tuvo entonces un medio de expresión y comunicación pero también patterns de movimiento, pura danza. Fue el comienzo del sistema más antiguo de comunicación, el Hmmmm (bolístico, manipulativo, multimodal, mimético y musical) que en el Homo Sapiens, al poder segmentarse, se separó en música y lenguaje. El Hmmmm fue un sistema de comunicación compuesto por varias emisiones holísticas, donde cada emisión es un mensaje en sí mismo. En él no hubo combinaciones de unidades discretas y jerárquicas como en el lenguaje. No hubo nada semejante a palabras como "chicas" donde el morfema "a" señala el género femenino y el morfema " $\mathrm{s}$ " indica que se trata de más de una. Nada semejante al morfema "aba" que, al combinarse en alguna palabra como "caminaba", representara la noción de tiempo pasado que transcurre de forma continua. $\mathrm{Ni}$ variaciones bruscas de sentido según el orden en que se presentaran las unidades discretas que constituían la frase, como sucede si en lugar de decir "la chica quebró el silencio" decimos "el silencio quebró a la chica". Como indica Tomás Moro Simpson (1964/1975), en las oraciones del lenguaje, como por ejemplo, en "Juancito es gordo", donde "Juancito" refiere a un supuesto hipopótamo, el pensamiento discursivo efectúa un análisis, distingue al hipopótamo de su gordura, realiza una descomposición de un todo divisible en partes. Pero si en el lugar de la proposición lo que se presenta es una imagen, ya no es posible efectuar un análisis, separar a Juancito de su gordura. No se puede tener uno sin el otro, la imagen constituye una unidad indivisa. Algo semejante sucedía con el Hmmmm. No estuvo conformado por imágenes o dibujos pero sí por unidades indivisibles de sonidos, movimientos y acciones desplegándose en el tiempo. No era posible extraer de sus frases una parte que significara "carne", por ejemplo, y usarla en diferentes contextos con el mismo significado. No existía un único término, "carne", que pudiera usarse en contexto de caza o de troceado del cadáver o de comida. Entonces cada frase era un mensaje en sí mismo. Una unidad indivisible que se aprendía, se emitía y se entendía como una unidad. Debe haber habido por tanto un número limitado de mensajes. Pero con ellos se podían hacer muchas cosas, como pedir, advertir, imponer, saludar, amenazar, apaciguar.

Hoy cuesta imaginárnoslo, dice Mithen, porque hemos perdido el lenguaje corporal. Pero quedan en nosotros remanentes del Hmmmm, como los gestos espontáneos. Pero la cosa más cercana al Hmmmm que conservamos en la actualidad es para él "el hablar con los bebés" (el habla o las performances dirigidas al bebé). Como el Homo Ergaster y el Homo Neardental hoy cantamos y hablamos a los bebés para hacerlos sonreír, mover, dormir, para confortarlos cuando están físicamente separados. La semejanza disminuye al año de edad cuando los niños modernos empiezan a segmentar sonidos y los padres ajustan sus actividades al desarrollo del niño para andamiar el proceso de adquisición del lenguaje. Pero durante los primeros meses de vida del bebé, es factible que todos los rasgos del $\mathrm{Hmmmm}$ se encuentren en la estimulación adulta.

Me he detenido sólo en el primer rasgo -la $\mathrm{H}$ de holístico- pero los otros, como la multimodalidad, la musicalidad o la mímesis son también esenciales. El $\mathrm{Hmmmm}$ hizo un uso vasto de ritmos, melodías, timbres y tonos especialmente para la expresión de estados emocionales y empleó extensamente también sus variaciones dinámico-expresivas. La mímica, la generación de sonidos y movimientos con variaciones dinámicas, rítmicas, tímbricas y melódicas fueron todos 
rasgos característicos del Hmmmm que han sido también encontrados, de una manera u otra, en la estimulación que los adultos modernos ofrecen a los bebés. Sin embargo, su carácter holístico es un rasgo distintivo que creo que no ha sido indagado en la estimulación adulta. Mithen no quiso referirse al Hmmmm ni como proto-lenguaje ni como proto-música porque consideró que su holismo lo distingue de ambos. La música y el lenguaje emergen en el Homo Sapiens cuando se torna posible segmentar las frases holísticas del Hmmmm. Tengo la impresión que el holismo es un rasgo que se percibe y cobra relieve si se presta atención al movimiento. El trabajo de Mithen abre varias preguntas. ¿Brindarán los adultos modernos con sus movimientos y sonidos unidades no compuestas por elementos discretos, combinables y jerárquicamente relacionados sino unidades de sentido indivisibles?, o lo que es lo mismo, ¿se organizarán los movimientos del adulto (y también sus sonidos) en frases holísticas? ¿Incitará la estimulación adulta en los bebés el reconocimiento de unidades indivisibles de sentido?, ¿será la estimulación adulta un estímulo para la actividad cognitiva de generación de unidades? Pero la estimulación adulta ¿no favorecerá también la capacidad de segmentación si se le ofrecen al bebé una tras otra, ininterrumpidamente, por que sí, unidades holísticas de movimiento?

\section{Escenas de sonido y movimiento}

Miall y Dissanayake (2003) analizaron el habla dirigida al bebé usando las herramientas propias del análisis literario y encontraron que, a pesar de la simpleza de sus contenidos semánticos y de su poca elaboración sintáctica, pueden identificarse rasgos poéticos, como una métrica repetitiva regular (en el uso de palabras cortas de una o dos sílabas), la organización de las emisiones en líneas de una duración semejante a la que caracterizan al verso (3 ó 4 seg.), la repetición de estrofas, así como aliteraciones, asonancias, hipérboles, etcétera. Su trabajo muestra lo adecuado y fértil que puede resultar analizar lo que los adultos hacen con sus bebés con las categorías de análisis de las artes, en su caso de la poesía. Siguiendo su idea, me gustaría comentar los rasgos que salen a luz si se analiza la estimulación adulta con las categorías de la danza. Conviene entonces que previamente indique algunas cuestiones acerca del análisis del movimiento en danza.

El estudio del movimiento no ha logrado la precisión del estudio del sonido pero aún así el Análisis del Movimiento de Rudolf Laban $(1970 / 1989,1971)$ con las modificaciones incorporadas por Bartenieff y Lewis (1980) ha alcanzado cierto grado de sistematización. En él se describe el movimiento a través de cinco categorías: cuerpo espacio, forma, energía y flujo.

Cuerpo: refiere las partes del cuerpo que son usadas en el movimiento. En nuestro caso hemos incorporado también el uso de objetos.

Espacio: da cuenta del uso del cuerpo en el espacio circundante. Alrededor del cuerpo está la kinesfera cuya circunferencia puede alcanzarse con las extremidades extendidas sin cambiar la postura. La kinesfera sirve para determinar las direcciones del movimiento en relación al espacio que lo circunda. Se distinguen cuatro posibles actitudes del cuerpo en el espacio de acuerdo a las dimensiones: vertical (arriba- abajo), horizontal (derecha-izquierda) y sagital (adelante-atrás).

Forma: describe los cambios constantes en la forma del cuerpo hecha en el espacio. Las cualidades de formas que se observan son extensiones de la oposición básica de apertura y cierre de la respiración en los planos vertical, horizontal y sagital. A saber: elevarse-bundirse, extenderse-encogerse, avanzar y retroceder.

Energía: refiere a la cualidad del movimiento y frecuentemente se lo compara con los términos dinámicos musicales (legato, forte, dolce). Está determinada por la 
actitud de entrega o lucha hacia los factores: peso, espacio y tiempo. El factor peso describe la fuerza del movimiento y puede ser firme o liviano. El tiempo puede ser súbito o sostenido. El factor espacio indica la atención al medioambiente y puede ser directa (o focalizada) o indirecta (dispersa). La combinación de la actitud de entrega o lucha a los factores de peso, espacio y tiempo da lugar a ocho tipos básicos de movimientos: presionar (directo-firme-sostenido), retorcer (flexible-firme-sostenido, deslizar (liviano-directo-sostenido), flotar (flexibleliviano-sostenido), golpear con un puño (directo-firme-súbito), arremeter (flexiblefirme-súbito), dar toques ligeros (liviano-directo- súbito), dar latigazos ligeros (flexible- liviano- súbito). Así, presionar (firme-directo-sostenido) implica luchar contra el peso y el espacio (producir una fuerte resistencia y seguir un empuje unidireccional) y abandonarse al tiempo (sostener la acción durante un período determinado). Dar latigazos leves: es un movimiento que surge de abandonarse al peso (aflojar la tensión muscular y lograr una sensación de ligereza) y al espacio (abandonarse al tirón unidireccional y rendirse a la sensación de ubicuidad) combinado con luchar contra el tiempo (acelerar la acción de modo que ocurra en un breve período de tiempo). Flotar surge de una actitud indulgente, arremeter de una actitud de lucha hacia el peso y el tiempo y abandono al espacio. Dar toques ligeros tiene dos elementos de lucha y uno de indulgencia (lucha con el espacio y el tiempo, abandono al peso). La figura 1 muestra los ocho movimientos básicos posibles.

FIGURA 1

Los ocho movimientos básicos según la actitud de lucha o entrega hacia el espacio, el tiempo y el peso

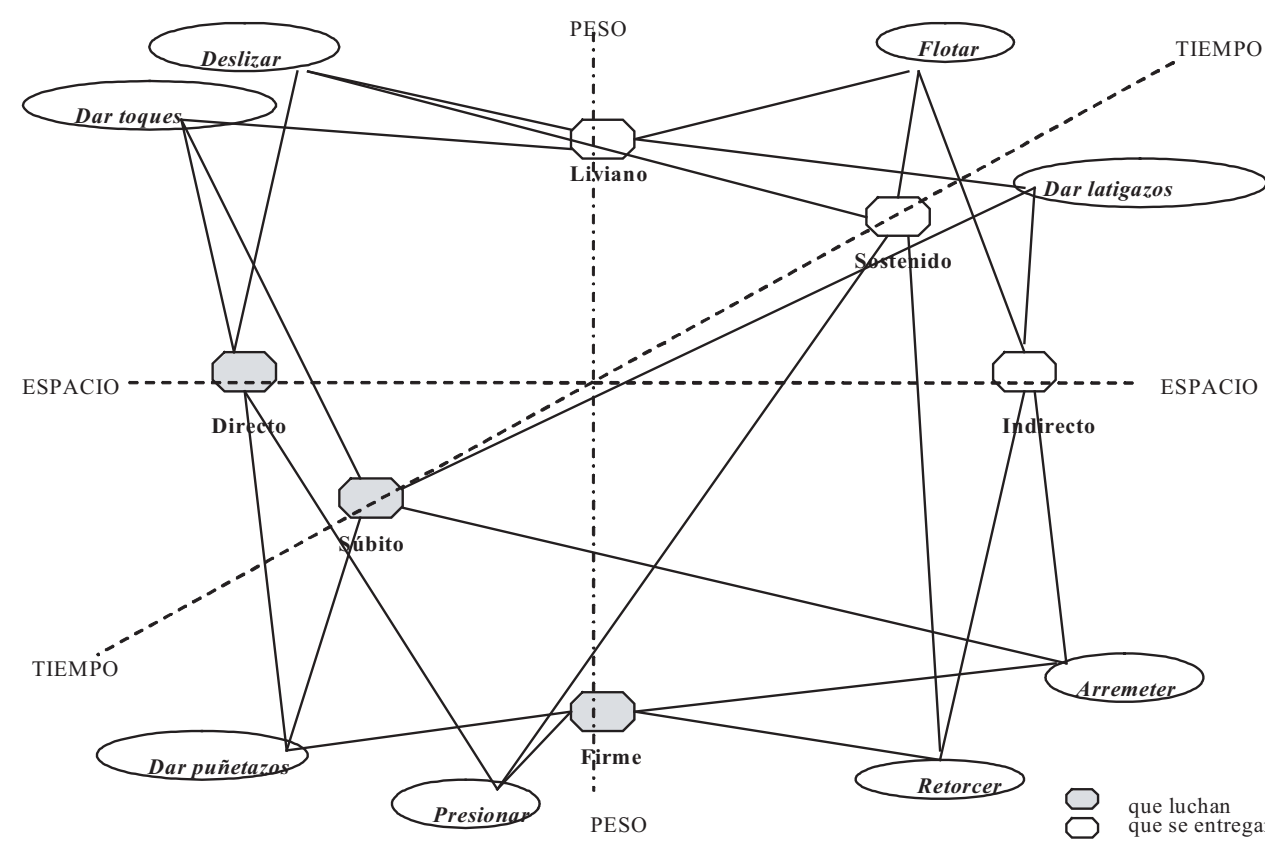

Flujo: Cada uno de estos ocho movimientos experimenta un flujo que puede ser libre o conducido. Un movimiento tiene un flujo conducido cuando puede ser detenido y contenido sin dificultad en cualquier momento. Y es libre cuando cuando es difícil detener y contener el movimiento en cualquier momento. 
Algunos flujos tienden a asociarse con cierto tipo de energía. Así retorcer y presionar tienen un flujo conducido a diferencia de dar latigazos ligeros cuyo flujo es libre. Otros como flotar pueden experimentarse tanto de modo libre como conducido.

Un movimiento no puede ser seguido por cualquier otro. Las secuencias de movimientos suelen realizarse cambiando un sólo factor de energía, cambiar dos elementos a la vez es difícil, tres es casi imposible y requiere de toda la concentración del bailarín. Hay por tanto secuencias posibles de movimientos como: retorcerse, presionar, deslizarse, flotar y dar latigazos y otras imposibles. Los modos del movimiento, unos en secuencia con otros, forman una especie de melodía u oración, una frase de movimientos. Es decir, en danza, la forma del movimiento, el uso del cuerpo y del espacio y el control de la energía como determinante de los rasgos dinámicos y expresivos delinean la organización del movimiento en frases.

\section{La elaboración del movimiento en la estimulación adulta}

$\mathrm{Al}$ inicio de este artículo dije que los adultos provistos tan sólo de pautas de mirada, sonidos y movimientos llaman a sus bebés al mundo emocional y les suavizan el mundo interpretándoles estímulos provenientes del medio. $\mathrm{Y}$, en el punto anterior, insinué que si la estimulación adulta es un remanente del Hmmmm deberá conservar algo de su holismo idiosincrásico; es decir, en algún nivel relevante deberá estar conformada por frases o unidades indivisibles de sentido. En lo que sigue intentaré mostrar que el análisis del movimiento, si se realiza con las categorías de la danza, puede sacar a luz cómo los adultos llaman a los bebés a la experiencia sentimental y les interpretan el mundo a través de frases holísticas. Lo que comentaré forma parte de un trabajo conjunto en el que realizamos un estudio microgenético de una breve escena video-grabada de interacción espontánea entre un adulto y un bebé de 7 meses. Favio Shifres (2007) observó la locución del adulto con las herramientas provenientes de los estudios en ejecución musical. Isabel Martínez (2007), aplicando las categorías de composicionalidad y motivo propias del análisis musical, examinó el conjunto de la actuación espontánea del adulto en la interacción con el bebé. Yo analicé el movimiento del adulto (Español, 2007b) utilizando el sistema de Análisis del Movimiento Laban-Bartenieff. Puede encontrarse el texto completo de los tres trabajos en www.sacoom.org.ar

Seleccionaré algunos aspectos puntuales del análisis realizado en Español (2007b) que permitan ilustrar nuestras observaciones e interpretaciones preliminares. Manteniendo el predominio del movimiento en la descripción, haré unos pocos comentarios sobre el sonido o el habla del adulto en relación con el movimiento. A continuación, una breve síntesis de la escena de interacción analizada.

Breve relato de la escena. El bebé está sentado en una sillita que posee varios puntos de reclinación. La adulta está sentada en el piso frente a él. La escena comienza con un movimiento casi casual con el que el adulto retira la manta que está encima del bebé, y continúa con la reiteración de poner y retirar la manta del regazo del infante mientras dice "ila sacamos?” .... "la saco, la saco, la saco" ... "ú-uh-pate". Luego el adulto se esconde detrás de la manta extendida, y la retira hablándole al bebé. En ese momento suena un teléfono y se producen una serie de movimientos y sonidos hasta que se retoma el juego de esconderse tras la manta. El bebé intenta llevarse la manta a la boca, el adulto se acerca para sacársela y la sillita se reclina repentinamente dos puntos hacia abajo. El adulto mueve la manta hacia arriba y abajo mientras dice " $\mathrm{U}$ y!!, toc-toc”... “¿qué pasó?”, realiza luego gestos de aflicción y dice "ay...qué le pasó?” ... “toctoc" mientras mueve suavemente la sillita. Se inclina buscando mayor intimidad "Esa ca... esa carita...esa caritita". Le toma la mano y la agita mientras dice "dientecitos ... un montón de dientecitos mordedor...sí, una enormidad de dientecitos tenés vos... una enormidad..." le 
toca el pecho con los dedos “ ¿qué vas a hacer con tanto dientes...? El bebé da vuelta la cabeza y finaliza el intercambio.

Si se observa la escena prestando atención sólo al movimiento se reconocen en ella fácilmente cuatro frases. La primera frase se inicia con un movimiento casi casual con el que el adulto retira la manta que está encima del bebé; seguidamente el movimiento de retirar la manta se elabora y luego la frase se cierra abandonando el objeto. Con un poco más de detalle la frase puede describirse así:

(a) Unidad inicial: movimiento de tronco y objeto con energía "deslizar", forma "retroceder", plano sagital y uso de objeto.

(b) Elaboración de la unidad inicial mediante ornamentación y repetición. Ornamentación de la energía del movimiento -que pasa de "flotar" a "deslizarflotar"- y de la forma -que pasa de "retroceder" a "elevarse-avanzar-hundirse y retroceder"- Tres repeticiones de la unidad ornamentada con variaciones dinámicas del movimiento. La información sonora se acopla con el movimiento; por ejemplo, la tercera repetición del movimiento "deslizar" es sincrónica y tiene la misma duración que el sonido piano y stacatto de la voz del adulto que dice "la saco, la caso, la saco". A su vez, llama la atención no sólo la concordancia sino la orquestación entre las variaciones del movimiento y del sonido: el movimiento ligado del deslizar parece una combinación cruzada con el staccatto del sonido "la saco la saco la saco" de modo semejante a como en danza la combinación cruzada del movimiento (por ejemplo, dando mayor velocidad y amplitud al largo del paso pero menor intensidad y fluidez) permite el staccato. En este caso la ligadura y fluidez del movimiento de deslizar se combina acentuando el staccatto sonoro.

(c) La frase se cierra simplificando el movimiento: se deja de lado el objeto y la forma simple "avanzar y retroceder" sustituye la más compleja "elevar-avanzarhundirse y retroceder". El movimiento de "avanzar" del final es el más prolongado de toda la frase y el adulto ofrece al bebé una misma información temporal (la duración) en el movimiento de avance hacia él y en la emisión sonora "ú-uhpate". El movimiento alternado "retroceder" cierra la frase retornando el adulto al centro de la kinesfera.

Como puede observarse los movimientos que realiza el adulto se organizan de inmediato en la forma repetición-variación, elemento básico de la elaboración, de acuerdo con Dissanayake (2000a), y de la música, de acuerdo con Imberty (2002). El cierre de la frase es nítido, el adulto retorna al centro de su kinesfera y seguidamente inicia otra frase de movimiento que se distingue por el cambio de uso del espacio, de la energía predominante y de la forma del movimiento. La frase semeja una performance multimedia que ha podido iniciarse, desarrollarse y concluirse en un movimiento de ornamentación y posterior simplificación de una unidad de movimiento inicial. La elaboración del movimiento concita la atención del bebé, ha logrado conformar un espectáculo que lo atrapa y lo reclama para el intercambio social y profundiza el estado de mutualidad entre ambos.

Pero las frases de movimiento del adulto no sólo se constituyen de esta manera. Hay en la escena una frase muy breve (la frase 3), de apenas seis segundos, en la que no se observa una unidad inicial y una elaboración posterior del movimiento. La frase encuentra su origen en un estímulo intenso y sorpresivo proveniente del medio ambiente -la sillita del bebé sorpresivamente cae dos veces produciendo ruido- y toda ella parece una interpretación del estímulo que afecta directamente al bebé. La energía del movimiento de caída de la sillita es "directa, súbita y firme" (golpear con el puño) y la respuesta del adulto es inmediata: inicia una unidad de movimiento variando sólo el elemento peso y produciendo, con el objeto que tiene en mano, por dos veces, un movimiento breve "liviano, directo y súbito" (dar toques ligeros) que conserva el plano del movimiento de la 
silla y que se aúna con la emisión "toc toc" de la misma duración. Luego el adulto recoge los brazos en un movimiento de "deslizar" y "flotar" y se extiende para imprimir a la silla dos nuevos y muy suaves "toques ligeros", como de suave balanceo, que coinciden en duración con la repetición del sonido "toc toc". Se cierra la frase con una breve pausa con contacto ocular.

Esta frase parece tener una única función: interpretar el estímulo excesivo del medio que pudo haber despertado en el bebé sentimientos de agitación, irrupción o brusquedad; busca que se distienda el sentimiento temporal mediante una labor hermenéutica llevada a cabo con movimientos (y también sonidos) que al ser elaborados reciben otro sentido. La interpretación del adulto es simple: repetir el movimiento, posiblemente disruptivo para el bebé, pero fuera del cuerpo del bebé, con el objeto y variando su único elemento de brusquedad, el peso. La caída "directa, súbita y firme" que el bebé siente en su cuerpo se transforma en una caída "directa, súbita pero liviana" que conserva el plano vertical de la otra caída pero que es vista afuera, en el objeto. La interpretación es un signo diferente pero semejante al percibido antes por el bebé y se acentúa con información redundante dada en la modalidad auditiva (el "toc toc"). Los "toctoc" forman parte de una compleja emisión sonora del habla del adulto cuyos rasgos musicales - de pulsación y articulación- están también al servicio de la regulación (Shifres, 2007). La frase no es otra cosa que una elaboración del ruido y del golpe de la sillita al caer cuya única función es modificar el sentimiento temporal que ruido y golpe pudieron haber despertado en el bebé. El final de la frase descubre su destino: sólo un instante de quietud, de pausa del movimiento, con un contacto ocular sereno. Una vez que la tranquilidad se ha restablecido entonces puede iniciarse otra frase, la última, que será como la primera una elaboración para el contacto intersubjetivo.

En la última frase, el adulto por primera vez realiza movimientos sobre el cuerpo del bebé. El movimiento presenta una curva de ascenso: el movimiento inicial de "deslizar" da paso al de tipo "toques ligeros", lo cual implica una aceleración de la velocidad del movimiento que conduce a un aumento de la excitación, los patrones temporales sonoros se acoplan al tempo del movimiento. La elaboración se muestra como una "composición" de sonido y movimiento (Martínez, 2007) que responde simplemente a la búsqueda de contacto con el bebé, vuelve a ser un reclamo para la vida social en el cual se experimenta la ornamentación y la complejidad de los modos de sentir temporales. Es el momento de mayor cercanía entre adulto y bebé, las sonrisas, palabras y balbuceos se mezclan. Cuando el adulto retrocede y vuelve al centro de su kinesfera, el bebé, probablemente regulando el fluir de sentimientos temporales, desvía la mirada poniendo fin a la frase y a la escena.

\section{Breve comentario final}

El análisis microgenético de la escena de interacción muestra que la elaboración de movimientos simples y cotidianos (como retirar una manta) genera un espectáculo que atrapa la atención del bebé y lo reclama para el intercambio social. En tal caso, la elaboración se orienta a profundizar el estado de mutualidad entre bebé y adulto mediante el fluir de sentimientos temporales compartidos. Pero la actuación del adulto puede estar motivada por la contingencia de estímulos del medio y cumplir una función hermenéutica en la que la elaboración de sonidos y movimientos "interpreta" los estímulos disruptivos del medio, regulando la excitación y modelando los sentimientos del infante (como ocurre con la caída de la sillita o en el sonido del teléfono). Pero ya se trate de una elaboración para la mutualidad o de una elaboración hermenéutica, ella no se realiza mediante 


\section{Estudios de Psicología, 2008, 29 (1), pp. 81-101}

toques aislados o intermitentes sino mediante frases holísticas e ininterrumpidas de sonidos y movimientos. Los adultos movemos el cuerpo pero también movemos el sonido, lo coloreamos, brindando desde el inicio unidades de sentido transmodales con múltiples perfiles de activación que inducen variados sentimientos temporales. Brindamos unidades redundantes de movimiento, sonido y sentimiento que estimulan y favorecen en el bebé el procesamiento cognitivo complejo de generación de unidades de sentido. Y probablemente al mismo tiempo estimulamos su capacidad de segmentación porque le ofrecemos una tras otra, ininterrumpidamente, frases de sonidos y movimientos que pueden diferenciarse unas de otras. La generación de unidades de sentido, por un lado, y la segmentación de unidades, por otra, son puertas que abren la entrada al mundo humano de unidades holísticas y discretas de significado. La argumentación teórica y el análisis empírico desarrollado en este trabajo inducen a pensar que los adultos movemos manos, brazos, cabeza, ojos, el cuerpo entero para guiarlos hacia allí. Y a la par los introducimos en el mundo de los sentimientos temporales, en la incertidumbre y en lo posible, en la expectativa y en la sorpresa. Les mostramos lo mismo que varía, dándoles información, a veces redundante otras orquestada, de sonidos y movimientos que se inician desarrollan y terminan y se inician de nuevo en un ciclo que culminará cuando el bebé, el adulto o las contingencias del mundo lo indiquen. Hacemos todo esto en mayor o menor grado; pero tan inevitablemente como hablamos, elaboramos sonidos y movimientos.

\section{Referencias}

BAHRICK, L. E. \& WATSON, J. S. (1985). Detection of intermodal proprioceptive-visual contingency as a potential basis of self-perception in infancy. Developmental Psychology, 21 (6), 963-973

BAHRICK, L. E. \& LICKLITER, R. (2000). Intersensory redundancy guides attentional selectivity and perceptual learning in infancy, Developmental Psychology, 36, 190-201.

BAHRICK, L. E., FLOM, R. \& LICKLITER, R. (2002). Intersensory redundancy facilitates discrimination of Tempo in 3-MonthOld Infants, Developmental Psychology, 41, 4, 352-63.

BarteniefF, I. \& LeWIS, D. (1980). Body Movement: Coping with the Environment. Nueva York: Gordon and Breach Science Publishers.

DissanaYAKE, E. (1992). Homo Aestheticus. Seattle: University of Washington Press.

DISSANAYAKE, E. (2000a) Art and Intimacy. How the Arts Began. Seattle y Londres: University of Washington Press.

DissanAYAKE, E. (2000b). Antecedents of the temporal arts in Early mother-infant Interaction. En N. L. Wallin, B. Merker \& S. Brown (Eds.), The Origins of Music (pp. 389-410). Cambridge, MA: The MIT Press.

DISSANAYAKE, E. (2001). Becoming Homo Aestheticus: source of aesthetic imagination in mother-infant interactions. Substance, 94/95, 85-103.

ESPAÑOL, S. (2006). De las emociones darwinianas a los afectos de la vitalidad o del tiempo de la evolución al tiempo del devenir. Revista de Historia de la Psicología, 2/3,13-21.

EspaÑoL, S. (2007a). Time and Movement in Symbol Formation. En J. Valsiner y A. Rosa (Eds.), The Cambridge Handbook of Socio-Cultural Psychology (pp. 238-255). Nueva York: Cambridge University Press

EsPAÑOL, S. (2007b). La elaboración del movimiento entre el bebé y el adulto. En M. P. Jacquier \& A. Pereira Ghiena (Eds.), Música y Bienestar Humano. Actas de la VI Reunión de SACCoM (pp. 3-12). Buenos Aires: SACCoM

Huron, D. (2003). Is music an evolutionary adaptation? En I. Peretz \& R. Zatorre (Eds.), The Cognitive Neuroscience of Music (pp. 57-75). Oxford: University Press.

IMBERTY, M. (2002). La musica e il bambino. En J.-J. Nattiez (Dir.), Enciclopedia della musica (pp. 477-495). Torino: Giulio Einaudi Editore.

KugIUMUTZAKIs, G. (1998). Neonatal imitation in the intersubjective companion space. En S. Brâten (Ed.), Intersubjective, communication and emotion in early ontogeny (pp. 63-88). Cambridge: Cambridge University Press.

Laban, R. (1970/1989). Danza Educativa Moderna. México: Ediciones Paidós.

LABAN, R. (1971). The mastery of movement. Boston: Plays.

LEWKOWICZ, D. (1992). Infants' response to temporally based intersensory equivalence: the effect of synchronous sounds on visual preferences for moving stimuli. Infant Behavior and Development, 15, 297-324.

LewKowICZ, D. (2002). Heterogeneity and heterochrony in the development of intersensory Perception. Cognitive Brain Research, 14, 41-63

LONGHI, E. (2003). The temporal structure of mother-infant interactions in musical contexts. PhD Thesis, The University of Edinburgh.

LONGHI, E. \& KARMILOFf-SMITH, A. (2004) In the beginning was the song: The complex multi-modal timing of motherinfant musical interaction. Behavioural and Brain Sciences, 27 (4) 516-517.

MALLOCH, S. (1999/2000). Mothers and infants and communicative musicality. Musicce Scientice, Special Issue, 29-57.

MARTíneZ, I. C. (2007). La composicionalidad de la performance adulta en la parentalidad intuitiva. En M. P. Jacquier \& A. Pereira Ghiena (Eds.), Música y Bienestar Humano. Actas de la VI Reunión de SACCoM (pp. 25-37). Buenos Aires. SACCoM. 
Meltzoff, A. N. \& MoOre, M. K. (1998). Infant intersubjectivity: broadening the dialogue to include imitation, identity and intention. En S. Brâten (Ed.), Intersubjective Communication and Emotion in Early Ontogeny (pp. 47-62). Cambridge: Cambridge University Press.

Miall. D. \& DissanaYaKe, E. (2003). The poetics of babytalk. Human Nature, 14 (4), 337-364.

Miller, G. (2000). Evolution of human music hrought sexual selection En N. L. Waliin, B. Merker \& S. Brown (Eds.), The Origins of Music (pp 328-360). Cambridge, MA: The MIT Press.

Mithen, S. (1996/1998). Arqueología de la mente. Orígenes del arte, la religión y la ciencia. Barcelona: Ed. Critica.

Mithen, S. (2006). The Singing Neanderthals: The Origins of Music, Language, Mind, and Body. Cambridge: Harvard University Press.

PAPÔUSEK, M. (1996). Intuitive parenting: a hidden source of musical stimulation in infancy. En I. Deliège \& J. A. Sloboda (Eds.), Musical Beginnings. Origins and Development of Musical Competence (pp. 88-112). Oxford: University Press.

Picó Sentelles, D. (2005). Filosofía de la escucha. El concepto de música en el pensamiento de Friedrich Nietzsche. Barcelona: Crítica.

PINKER, S. (1997/2001). Cómo funciona la mente. Barcelona: Destino.

Rivière, A. (1986/2003). Interacción precoz. Una perspectiva vygotskiana a patir de los esquemas de Piaget. En M. Belinchón, A. Rosa, M. Sotillo \& I. Marichalar (Comps.), Angel Rivière. Obras Escogidas, Vol II (pp. 109-142). Madrid: Panamericana.

Rochat, PH. (2000/2004). El mundo del bebé. Madrid: Morata.

SHIFRES, F. (2007). La ejecución parental. Los componentes performativos de las interacciones tempranas. En M. P. Jacquier \& A. Pereira Ghiena (Eds.), Música y Bienestar Humano. Actas de la VI Reunión de SACCoM (pp. 13-24). Buenos Aires. SACCOM.

Simpson, T. M. (1964/1975). Formas Lógicas, realidad y significado. Buenos Aires: Eudeba

STERN, D. (1985/1991). El mundo interpersonal del infante. Una perspectiva desde el psicoanálisis y la psicología evolutiva. Buenos Aires: Paidós

STERN, D. (2000). Putting time back into our considerations of infant experience: a microdiachronic view. Infant Mental Health Journal, 21 (1-2), 21-28.

Trenub, S. (2000). Human Processing Predispositions and Musical Universals. En N. L. Waliin, B. Merker \& S. Brown (Eds.) The Origins of Music (pp. 427-448). Cambridge, MA: The MIT Press.

Trenub, S. (2003). Musical Predispositions in Infancy: an update. En I. Peretz \& R. Zatorre (Eds.), The Cognitive Neuroscience of Music (pp. 3-20). Oxford: University Press.

Trevarthen, C. (1998). The concept and foundations of infant intersubjectivity. En S. Brâten (Ed.), Intersubjective Communication and Emotion in Early Ontogeny (pp. 15-46). Cambridge: Cambridge University Press.

Trevarthen, C. (1999/2000). Musicality and the intrinsic motive pulse: evidence from human psychobiology and infant communication. Musice Scientice, Special Issue, 155-215.

Watson, J. S. \& RAMmEY, C. T. (1972). Reactions to response-contingent stimulation in early infancy. Merrill-Palmer Quaterly, 18, 219-227. 